\title{
Implementation of Simple Additive Weighting Algorithm in Particular
} Instance

\author{
Muhammad Donni Lesmana Siahaan ${ }^{1}$, Elviwani ${ }^{2}$, Asprina Br. Surbakti ${ }^{3}$, Andre Hasudungan Lubis ${ }^{4}$, \\ Andysah Putera Utama Siahaan ${ }^{5}$ \\ ${ }^{1,5}$ Faculty of Computer Science, Universitas Pembangunan Panca Budi, Medan, Indonesia \\ ${ }^{2}$ Faculty of Computer Science and Information Technology, Universitas Sumatera Utara, Medan, Indonesia \\ ${ }^{3}$ Department of Informatics, Politeknik Poliprofesi Medan, Medan, Indonesia \\ ${ }^{4}$ Faculty of Engineering, Universitas Medan Area, Medan, Indonesia \\ ${ }^{5} \mathrm{Ph}$.D. Student of School of Computer and Communication Engineering, Universiti Malaysia Perlis, Kangar, \\ Malaysia
}

\begin{abstract}
In the problem of determining the proper level of sequence in a sorting problem, the Simple Additive Weighting (SAW) method is an easy-to-use technique. It can analyze cases based on the criteria used. The use of criteria values in this approach has an unlimited amount. The more criteria used, the higher the accuracy of the results obtained. There are two types of criteria, cost, and benefits. Cost is used if the higher the criterion value, the lower the chance to get the top score while the benefit is used if the higher the criterion value, the greater the chance to get the top position. This study explains how to apply SAW algorithm in solving sequence problems in various cases encountered. Using this method will solve decisions that can not be completed manually. It helps the admin in choosing the best decision in any particular instance.
\end{abstract}

Keywords : Rank, SAW, Expert System, DCS

\section{INTRODUCTION}

The problem often faced is the injustice in choosing a decision. There are cases where elections must be held back due to unfair decisions. On a small case selection, this may not be a problem. The use of large data such as large companies will require a system to support management decisions based on data on the company [1]. It is currently being developed with various methods is a decision support system. It was drawn up to decide solutions based on existing data. The data is processed with a mathematical calculation to produce a decision [2][5]. It is the dilemma for an institution to determine who or what is entitled to the first rank. This problem is often a controversy between employees done in a company in search of the best employees. Manual search is not always fair; it can be likes or dislikes. As the case progresses, the need for a decision support system is growing very high. Many methods can be used to find a solution, one of them is Simple Additive Weighting. Companies expect much by using decision methods; the results are the best thing to advance performance.

\section{Theories}

\section{A. Simple Additive Weighting}

The Simple Additive Weighting method is often known as the weighted summing method. The basic concept of the Simple Additive Weighting method is to find the weighted sum of performance ratings on each alternative on all attributes [3][4]. It can assist in the decisionmaking case, but the calculation using the method is only that produces the biggest value chosen as the best alternative. The calculation will be by this method if the selected alternatives meet the specified criteria. It is more efficient than other methods since the time required for the computation is shorter.

The SAW method requires the process of normalizing the decision matrix to a scale comparable to all current alternative ratings [6]. This method is the most famous and most widely used method of dealing with Multiple Attribute Decision Making (MADM) situations. MADM itself is a method used to find the optimal alternative of 
some alternatives with certain criteria. The SAW method requires decision makers to assign weights to each attribute [7]. The total score for the alternative is obtained by summing all the results of the multiplication between the rating and the weight of each attribute. The rating of each attribute must be dimensionless; it has passed the previous matrix normalization process.

There are several steps that must be taken in performing SAW calculation, such as:

- Define criteria as an appraiser to the advantages of a variable.

- Determine the match rate for each alternative for the criteria provided.

- Create a decision matrix based on criteria.

- Perform normalization based on benefits and cost on each attribute.

- Determining the final value based on the defining weights for each $\mathrm{R}$ value on the normalization matrix.

\section{B. Data Collection}

There are several types of data that need to be prepared before the SAW calculation [8]. The data are:

1. Criteria.

Criteria are data containing code, name, attribute, weight. The weight of the criteria determines how important the criteria are. Attributes consist of benefit or cost, where the benefit means the greater the value, the better, while the cost, the smaller the value, the better.

\section{Crisp}

Crisp is data that contains criteria, description, and weight codes. It is optional, i.e., like a barrier of the value of each criterion. Each crisp has its respective weights as in the above brackets. The weighting also affects the attributes of the criteria. Weighting should not be reversed.

3. Alternative

Alternative is an option to be calculated and selected as the best alternative. Alternate data usually contains the candidate's target. It is a ranking choice.

\section{Methodology}

Ordering is a complicated thing to do manually. There are many things to be considered. It aims to have the election on target. To facilitate administrators in making decisions to determine who is entitled to the rankings, it is necessary to consider the criteria as applicable requirements. In this section, the author will try to give examples of cases that occur in the selection order. For example, the election of a village head. There are several criteria proposed in the decision making can be seen in the following table.

Table 1. Criteria

\begin{tabular}{|c|l|l|}
\hline Criteria & Remark & Weight \\
\hline C1 & Education & 2 \\
\hline C2 & Health & 2 \\
\hline C3 & Dependence & 1 \\
\hline C4 & Age & 2 \\
\hline C5 & Income & 3 \\
\hline
\end{tabular}

There are five criteria in the trial. These criteria are Education, Health, Dependence, Age, and Income. The five criteria are aimed to choose the right people in an election. In the election, it is this that will be a careful consideration for who is entitled to the opportunity to sit as the village head. The match rating for each alternative on each criterion is as follows:

$\begin{array}{ll}\text { Very High } & =1 \\ \text { High } & =2 \\ \text { Enough } & =3 \\ \text { Low } & =4 \\ \text { Very Low } & =5\end{array}$

Each criterion has limits on the measured value. These values are different for each criterion. The following is the determination of the value for each of the criteria.

1. Education

There are several items that can be used as an educational criterion to determine the village head. The following table describes the criteria. 
Table 2 Criteria of Education

\begin{tabular}{|l|l|}
\hline C1 & Weight \\
\hline High School & 1 \\
\hline Diploma & 2 \\
\hline Bachelor & 3 \\
\hline Master & 4 \\
\hline Doctor & 5 \\
\hline
\end{tabular}

2. Health

There are several items that can be used as an health criterion. The following table describes the criteria.

Table 2 Criteria of Health

\begin{tabular}{|l|l|}
\hline C2 & Weight \\
\hline Very Weak & 1 \\
\hline Weak & 2 \\
\hline Enough & 3 \\
\hline Strong & 4 \\
\hline Very Strong & 5 \\
\hline
\end{tabular}

3. Dependence

There are several items that can be used as an dependence criterion. The following table describes the criteria.

Table 3 Criteria of Dependence

\begin{tabular}{|lr|l|}
\hline C3 & Weight \\
\hline $\begin{array}{l}\text { Husband/Wife } \\
\text { Children 3 }\end{array}$ & + & 1 \\
\hline $\begin{array}{l}\text { Husband/Wife } \\
\text { Children 2 }\end{array}$ & + & 2 \\
\hline $\begin{array}{l}\text { Husband/Wife } \\
\text { Children 1 }\end{array}$ & 3 \\
\hline Husband/Wife & 4 \\
\hline Single & 5 \\
\hline
\end{tabular}

4. Age

There are several items that can be used as an age criterion. The following table describes the criteria.

\begin{tabular}{|l|l|}
\hline $25-29$ & 3 \\
\hline $40-59$ & 4 \\
\hline $30-49$ & 5 \\
\hline
\end{tabular}

5. Income

There are several items that can be used as an income criterion. The following table describes the criteria.

Table 5 Criteria of Income

\begin{tabular}{|l|l|}
\hline C1 & Weight \\
\hline $1000 \mathrm{k}-2000 \mathrm{k}(\mathrm{IDR})$ & 1 \\
\hline $2000 \mathrm{k}-3000 \mathrm{k}(\mathrm{IDR})$ & 2 \\
\hline $3000 \mathrm{k}-4000 \mathrm{k}(\mathrm{IDR})$ & 3 \\
\hline $4000 \mathrm{k}-5000 \mathrm{k}(\mathrm{IDR})$ & 4 \\
\hline Above $5000 \mathrm{k}(\mathrm{IDR})$ & 5 \\
\hline
\end{tabular}

\section{Result and Discussion}

The test data are samples taken for experiment and testing of SAW algorithm in village head election. In this data, several names are taken as examples in the election of the village head. The following table describes the names and capabilities based on the criteria table in the previous chapter.

Table 5 Dataset

\begin{tabular}{|c|l|l|l|l|l|l|}
\hline No. & Name & C1 & C2 & C3 & C4 & C5 \\
\hline 1. & Agus & 2 & 3 & 4 & 5 & 2 \\
\hline 2. & Doni & 2 & 4 & 3 & 2 & 2 \\
\hline 3. & Ikhwan & 3 & 2 & 3 & 3 & 4 \\
\hline 4. & Reza & 4 & 2 & 4 & 2 & 4 \\
\hline 5. & Yogi & 5 & 1 & 2 & 4 & 3 \\
\hline
\end{tabular}

The above criterion is a benefit criterion in which each value in the criteria has the best value if the value is big. The decision maker gives the preference weight as: $\mathrm{W}=$ $(2,2,1,2,3)$. Decision matrix formed from the match table as follows:

$$
X=\left[\begin{array}{lllll}
2 & 3 & 4 & 5 & 2 \\
2 & 4 & 3 & 2 & 2 \\
3 & 2 & 3 & 3 & 4 \\
4 & 2 & 4 & 2 & 4 \\
5 & 1 & 2 & 4 & 3
\end{array}\right]
$$


The following values are the calculation of the normalization of the decision matrix by calculating the normalized performance rating value of each alternative based on the criteria assumed as the profit criterion.

\section{Alternatif 1 (1-5)}

$$
\begin{aligned}
\mathrm{R} 1,1 & =\frac{\min (2,2,3,4,5)}{2} \\
& =\frac{2}{2} \\
& =1
\end{aligned}
$$

$$
\begin{aligned}
\mathrm{R} 1,2 & =\frac{\min (3,4,2,2,1)}{3} \\
& =\frac{1}{3} \\
& =0,33
\end{aligned}
$$

$$
\begin{aligned}
\mathrm{R} 1,3 & =\frac{\min (4,3,3,4,2)}{4} \\
& =\frac{2}{4} \\
& =0,5
\end{aligned}
$$

$$
\begin{aligned}
\mathrm{R} 1,4 & =\frac{\min (5,2,3,2,4)}{5} \\
& =\frac{2}{5} \\
& =0,4
\end{aligned}
$$

$$
\begin{aligned}
\mathrm{R} 1,5 & =\frac{\min (2,2,4,4,3)}{2} \\
& =\frac{2}{2}
\end{aligned}
$$$$
=1
$$

\section{Alternatif $2(1-5)$}

$$
\begin{aligned}
\mathrm{R} 2,1 & =\frac{\min (2,2,3,4,5)}{2} \\
& =\frac{2}{2} \\
& =1 \\
\mathrm{R} 2,2 & \\
& =\frac{\min (3,4,2,2,1)}{4} \\
& =\frac{1}{4} \\
& =0,25 \\
\mathrm{R} 2,3 & =\frac{\min (4,3,3,4,2)}{3} \\
& =\frac{2}{3} \\
& =0,67
\end{aligned}
$$

$$
\begin{aligned}
\mathrm{R} 2,4 & =\frac{\min (5,2,3,2,4)}{2} \\
& =\frac{2}{2} \\
& =1 \\
\mathrm{R} 2,5 & =\frac{\min (2,2,4,4,3)}{2} \\
& =\frac{2}{2} \\
& =1
\end{aligned}
$$

\section{Alternatif 3 (1-5)}

$$
\begin{aligned}
\mathrm{R} 3,1 & =\frac{\min (2,2,3,4,5)}{3} \\
& =\frac{2}{3} \\
& =0,67 \\
\mathrm{R} 3,2 & =\frac{\min (3,4,2,2,1)}{2} \\
& =\frac{1}{2} \\
& =0,5
\end{aligned}
$$

$$
\begin{aligned}
\mathrm{R} 3,3 & =\frac{\min (4,3,3,4,2)}{3} \\
& =\frac{2}{3} \\
& =0,67
\end{aligned}
$$

$$
\begin{aligned}
\mathrm{R} 3,4 & =\frac{\min (5,2,3,2,4)}{3} \\
& =\frac{2}{3} \\
& =0,67
\end{aligned}
$$

$$
\begin{aligned}
\mathrm{R} 3,5 & =\frac{\min (2,2,4,4,3)}{4} \\
& =\frac{2}{4} \\
& =0,5
\end{aligned}
$$

\section{Alternatif 4 (4-5)}

$$
\begin{aligned}
\mathrm{R} 4,1 & =\frac{\min (2,2,3,4,5)}{4} \\
& =\frac{2}{4} \\
& =0,5 \\
\mathrm{R} 4,2 & =\frac{\min (3,4,2,2,1)}{2} \\
& =\frac{1}{2} \\
& =0,5
\end{aligned}
$$




$$
\begin{aligned}
\mathrm{R} 4,3 & =\frac{\min (4,3,3,4,2)}{4} \\
& =\frac{2}{4} \\
& =0,5 \\
\mathrm{R} 4,4 & =\frac{\min (5,2,3,2,4)}{2} \\
& =\frac{2}{2} \\
& =1 \\
\mathrm{R} 4,5 & =\frac{\min (2,2,4,4,3)}{4} \\
& =\frac{2}{4} \\
& =0,5
\end{aligned}
$$

\section{Alternatif 5 (1-5)}

$$
\begin{aligned}
\mathrm{R} 5,1 & =\frac{\min (2,2,3,4,5)}{5} \\
& =\frac{2}{5} \\
& =0,4 \\
\mathrm{R} 5,2 & =\frac{\min (3,4,2,2,1)}{1} \\
& =\frac{1}{1} \\
& =1 \\
\mathrm{R} 5,3 & =\frac{\min (4,3,3,4,2)}{2} \\
& =\frac{2}{2} \\
& =1 \\
\mathrm{R} 5,4 & =\frac{\min (5,2,3,2,4)}{4} \\
& =\frac{2}{4} \\
& =0,5 \\
\mathrm{R} 5,5 & =\frac{\min (2,2,4,4,3)}{3} \\
& =\frac{2}{3} \\
& =0,67
\end{aligned}
$$

After the processes are executed, the normalization value matrix will be obtained as shown below:

$$
R=\left[\begin{array}{ccccc}
1 & 0,33 & 0,5 & 0,4 & 1 \\
1 & 0,25 & 0,67 & 1 & 1 \\
0,67 & 0,5 & 0,67 & 0,67 & 0,5 \\
0,5 & 0,5 & 0,5 & 1 & 0,5 \\
0,4 & 1 & 1 & 0,5 & 0,67
\end{array}\right]
$$

Based on the weight set previously that $\mathrm{W}=[2,2,1,2$, 3] then the final value can be calculated using the previous formula.

\section{SAW Weight (V1-V5)}

$$
\begin{aligned}
\mathrm{V} 1= & (2 * 1)+(2 * 0,33)+(1 * 0,5)+ \\
& (2 * 0,4)+(3 * 1) \\
= & 2+0,66+0,5+0,8+3 \\
= & 6,96 \\
\mathrm{~V} 2= & (2 * 1)+(2 * 0,25)+(1 * 0,67)+ \\
& (2 * 1)+(3 * 1) \\
= & 2+0,5+0,67+2+3 \\
= & 8,17 \\
\mathrm{~V} 3 & (2 * 0,67)+(2 * 0,5)+(1 * 0,67)+ \\
& (2 * 0,67)+(3 * 0,5) \\
= & 1,34+1+0,67+1,34+1,5 \\
= & 5,85 \\
\mathrm{~V} 4 & (2 * 0,5)+(2 * 0,5)+(1 * 0,5)+ \\
& (2 * 1)+(3 * 0,5) \\
= & 1+1+0,5+2+1,5 \\
= & 6 \\
\mathrm{~V} 5= & (2 * 0,4)+(2 * 1)+(1 * 1)+ \\
& (2 * 0,5)+(3 * 0,67) \\
= & 0,8+2+1+1+2,01 \\
= & 6,81
\end{aligned}
$$

From the above calculation, V2 (8.17) is the highest value while V4 (6) is the lowest value. It can be seen that the one who deserves the position of the village head is Doni.

\section{Conclusion}

Determination of village head election can help the subdistrict office to select the candidate as expected. This method has the technique of assessing the rating of someone accurately. The criteria used can contribute to clarifying the value of accuracy generated. The use of few criteria will reduce the accuracy of the assessment. The criteria used should be better added by the performance and specifications of the elected people to be candidates for substitute of the previous village head to carry out village head assessments. 


\section{REFERENCES}

[1]. M. Iswan, Khairul and A. P. U. Siahaan, "Fuzzy Logic Concept in Technology, Society, and Economy Areas in Predicting Smart City," International Journal of Recent Trends in Engineering \& Research, vol. 2, no. 12, 2016.

[2]. A. P. U. Siahaan, "Fuzzification of College Adviser Proficiency Based on Specific Knowledge," International Journal of Advanced Research in Computer Science and Software Engineering, vol. 6, no. 7, pp. 164-168, 2016.

[3]. Khairul, M. Simaremare and A. P. U. Siahaan, "Decision Support System in Selecting The Appropriate Laptop Using Simple Additive Weighting," International Journal of Recent Trends in Engineering and Research, vol. 2, no. 12, pp. 215-222, 2016.

[4]. A. Afshari, M. Mojahed and R. M. Yusuff, "Simple Additive Weighting Approach to Personnel Selection Problem," International Journal of Innovation, Management and Technology, vol. 1, no. 5, pp. 511-515, 2010.

[5]. Mesran, K. Tampubolon, R. D. Sianturi, F. T. Waruwu and A. P. U. Siahaan, "Determination of Education Scholarship Recipients Using Preference Selection Index," International Journal of Scientific Research in Science and Technology, vol. 3, no. 6, pp. 230-234, 2017.

[6]. D. Pratiwi, J. P. Lestari and D. A. R., "Decision Support System to Majoring High School Student Using Simple Additive Weighting Method," International Journal of Computer Trends and Technology, vol. 10, no. 3, pp. 153-159, 2014.

[7]. P. Kaur and S. Kumar, "An Intuitionistic Fuzzy Simple Additive Weighting (IFSAW) Method for Selection of Vendor," IOSR Journal of Business and Management, vol. 15, no. 2, pp. 78-81, 2013.

[8]. J. Thor, S.-H. Ding and S. Kamaruddin, "Comparison of Multi Criteria Decision Making Methods From The Maintenance Alternative Selection Perspective," International Journal of Engineering And Science, vol. 2, no. 6, pp. 27-34, 2013. 